\title{
LAND USE/COVER CHANGE MODELLING IN A MEDITERRANEAN RURAL LANDSCAPE USING MULTI-LAYER PERCEPTRON AND MARKOV CHAIN (MLP-MC)
}

\author{
Mirici, M. E. ${ }^{1 *}-$ Berberoglu, S. $^{1}-$ AKIN, A. ${ }^{2}-$ SATIR, O. ${ }^{3}$ \\ ${ }^{1}$ Department of Landscape Architecture, Cukurova University \\ 01330 Adana, Turkey \\ ${ }^{2}$ Department of Regional and Urban Planning, Bursa Technical University \\ 16330 Bursa, Turkey \\ ${ }^{3}$ Department of Landscape Architecture, Yuzuncu Yil University \\ 65080 Van, Turkey \\ *Corresponding author \\ e-mail:mrversoy@gmail.com; memirici@cu.edu.tr \\ (Received $7^{\text {th }}$ Sep 2017; accepted 6 ${ }^{\text {th }}$ Dec 2017)
}

\begin{abstract}
Mediterranean land use and land cover (LULC) have a very dynamic structure as a result of continuous transformation process due to anthropogenic effects and environmental gradients. LULC dynamics are important indicator of environmental condition in temporal and spatial scales. The aim of this paper was to simulate the future LULC of a Mediterranean type watershed located at the Eastern Mediterranean Region of Turkey by incorporating multi-layer perceptron (MLP), artificial neural network (ANN) and Markov chain (MC) approaches. Landsat TM/OLI images in 1990, 2003 and 2014 over the study area were classified using hybrid classification approach. The Kappa statistics of the hybrid classification that combines K-means, decision tree and object based classification method for these three images were $0.81,0.85$ and 0.87 respectively. The LULC map of 2014 was simulated using LULC maps of 1990 and 2003 for calibration and validation. The simulation results were compared with the actual 2014 LULC map to assess the accuracy of the simulation, and the rate of overlap was found as $89 \%$. LULC map of 2025 was estimated using LULC maps of 2003 and 2014. These results indicated that, the area of bareground will reduce $13.31 \%$ whereas the rate of forest and agricultural area will increase $8.70 \%$ and $6.51 \%$ respectively.
\end{abstract}

Keywords: land use/land cover (LULC), hybrid classification, change detection, multi-layer perceptron $(M L P)$, Markov chain, future prediction

\section{Introduction}

Land use refers to man's activities on earth which are directly related to land, while land cover denotes the natural features of the land surface (Singh and Singh, 2011; Ozdogan, 2016). Land use dynamics are important elements for monitoring, evaluating, protecting and planning for earth and ecosystem goods and services (Jakubauskas et al., 1990). LULC which has a dynamic structure results in the change of ecosystem good and service potential due to the transformation. Ecosystem goods and services are the benefits people obtain from ecosystems. During the ecosystem process, there is a flux of energy and material from one pool to another. Terrestrial ecosystems currently store approximate four times more carbon than is found in the atmosphere. Changes in LULC due to timber harvesting, deforestation for agriculture and fire can release substantial amounts of terrestrially stored carbon (Chapin et al., 2011; Conte et al., 2011; Lal, 2004; 2011; Young et al., 2016). Additionally, forests play an iconic role in environmental conservation and are habitats for much of the world's terrestrial biodiversity. Remote 
sensing (RS) technologies are vital to understand the impact of anthropogenic activities and change in natural area. Satellite sensor imageries were used in geospatial investigations in last decades for policy and decision making (Masud et al., 2016). Satellite sensor based data is essential for the study both urban and rural management and planning. In this extent, Geographic Information System (GIS) and RS applications take on a critical role in modern era for natural resource management (Elaalem et al., 2013; Mercant and Narumalani, 2009).

Markov chain (MC) is a very useful approach to forecast urban or rural landscape transition. This approach became more popular due to improvement in GIS and RS technologies. Markov chain methodology intensively utilizes RS data to simulate LULC changes (Dadhich and Hanaoka, 2010a; 2010b; Muller and Middleton, 1994). The aim of this study was to predict the future change in the study area where the rural landscape structure is dominant. The LULC changes were modelled using classified maps derived from 1990, 2003 and 2014 images of Landsat TM/ETM. A hybrid classification approach which combines object-based, K-means and decision tree classification methods was used to increase the accuracy of these classifications. Predicted 2025 LULC map was derived incorporating ANN and MC approaches.

\section{Material and method}

\section{Study area}

The study area is located in the Eastern Mediterranean Region of Turkey. The region covers an area of approximately $7368.62 \mathrm{~km}^{2}$ and its altitude ranges between 37 and $3555 \mathrm{~m}$. The forest species richness is substantial and the area has a wide range of heterogeneous topography formed by Taurus Mountain Chain (Figure 1).

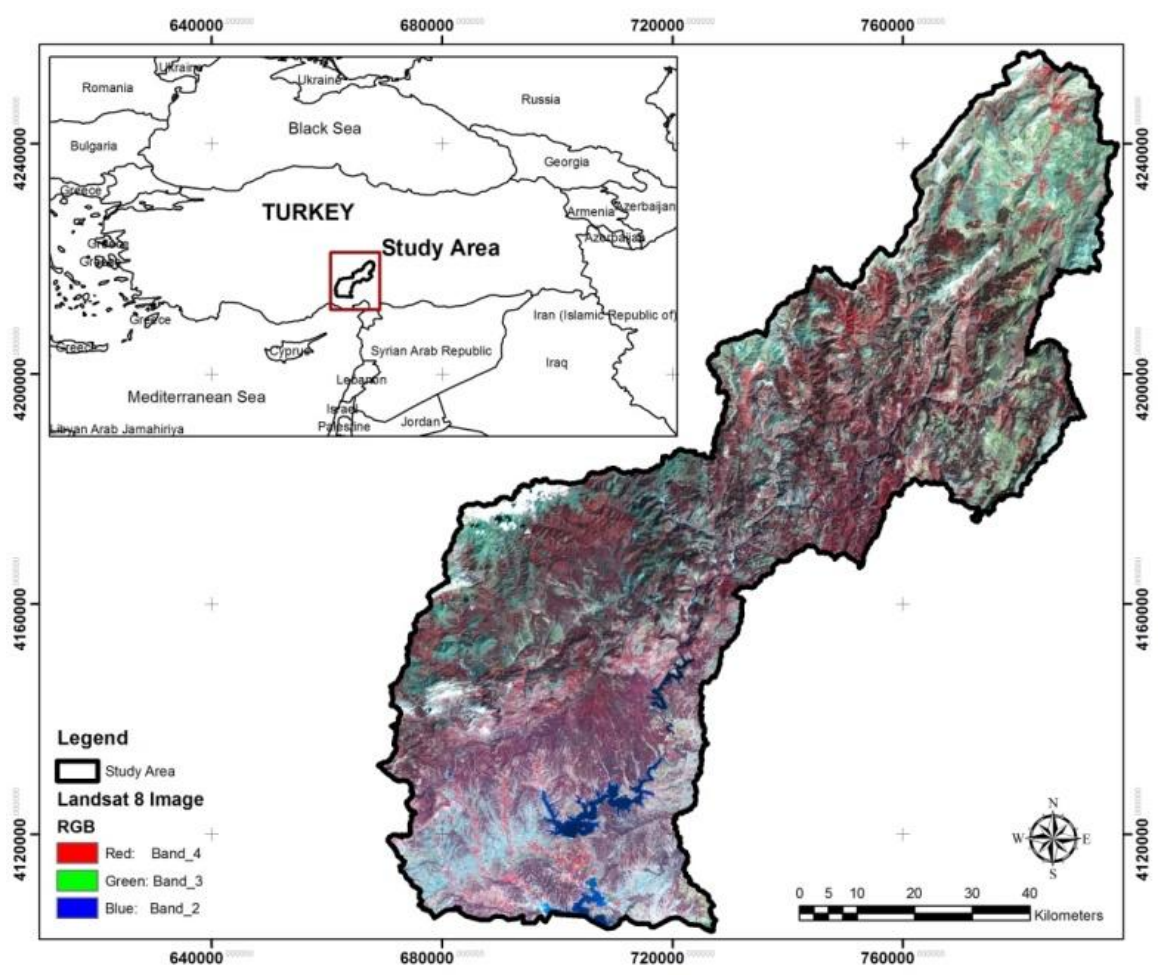

Figure 1. The geographical location of the study area 
This area has vast forest land due to the environmental gradients including variation in topography, climate and soils. Forests of southern of Turkey are one of the most important carbon sinks of Turkey. The region covers mostly pure and mixed conifers followed by some deciduous tree species (Donmez, 2016). The climate of the study area is characterized by mild and rainy winters and moist summers with a mean annual precipitation of around $800 \mathrm{~mm}$ and distribution of rainfall varies, approximately $75 \%$ of rainfall occurs in autumn and winter, the mean annual temperature is $19{ }^{\circ} \mathrm{C}$. Thus, the climate, rich water resources and fertile alluvial plane enabled this area the most productive agriculture region in Turkey.

\section{Characteristics of the dataset}

Different dates LULC classification maps were generated with using Landsat images. Additionally Landsat images were used for auxiliary variables that are including vegetation indices to be produced. The remotely sensed data used in this study were given in Table 1. The Landsat TM/OLI images were obtained from USGS. Spatial resolution of the dataset was $30 \mathrm{~m}$ resolution and georeferenced to UTM, WGS84 projection.

Table 1. Landsat images used for LULC mapping

\begin{tabular}{c|c|c|c|c|c|c}
\hline Sensor type & Image date & Patch & Rows & Bant & Radiometric resolution & Spatial resolution $(\mathbf{m})$ \\
\hline TM & 29.08 .1990 & 175 & $33 / 34$ & $1,2,3,4,5,7$ & 8 & 30 \\
TM & 17.08 .2003 & 175 & $33 / 34$ & $1,2,3,4,5,7$ & 8 & 30 \\
OLI TIRS & 13.09 .2014 & 175 & $33 / 34$ & $2,3,4,5,6,7$ & 16 & 30 \\
\hline
\end{tabular}

The auxiliary dataset was produced for study area LULC classification. Auxiliary variables used in decision tree classification are shown in Table 2. It was used decision tree rule with reflectance value on visible bands, vegetation indices and DEM.

Table 2. Auxiliary variables derived from satellite sensor data

\begin{tabular}{c|c|c}
\hline Auxiliary data & Data date & Metadata \\
\hline Visible bands & $1990-2003-2014$ & Landsat 5 TM - Landsat 8 OLI TIRS \\
NIR & $1990-2003-2014$ & Landsat 5 TM - Landsat 8 OLI TIRS \\
SWIR & $1990-2003-2014$ & Landsat 5 TM - Landsat 8 OLI TIRS \\
NDVI & $1990-2003-2014$ & Landsat 5 TM - Landsat 8 OLI TIRS \\
NDWI & $1990-2003-2014$ & Landsat 5 TM - Landsat 8 OLI TIRS \\
Tasseled Cap & $1990-2003-2014$ & Landsat 5 TM - Landsat 8 OLI TIRS \\
K-means & $1990-2003-2014$ & Landsat 5 TM - Landsat 8 OLI TIRS \\
Forest map & $2002-2014$ & Forest General Directorate \\
DEM & 2013 & SRTM \\
\hline
\end{tabular}

\section{Method}

This study included six stages; (i) pre-processing of multi-temporal remotely sensed images and forest maps, (ii) production of past (1990-2003) and current (2014) LULC maps using hybrid approach, (iii) accuracy assessment, (iv) modelling of 2014 LULC map, (v) validation of 2014 modelling and (vi) LULC simulation of 2025 (Figure 2). 
Land cover change analysis and future land cover modelling studies were carried out within IDRISI TerrSet software.

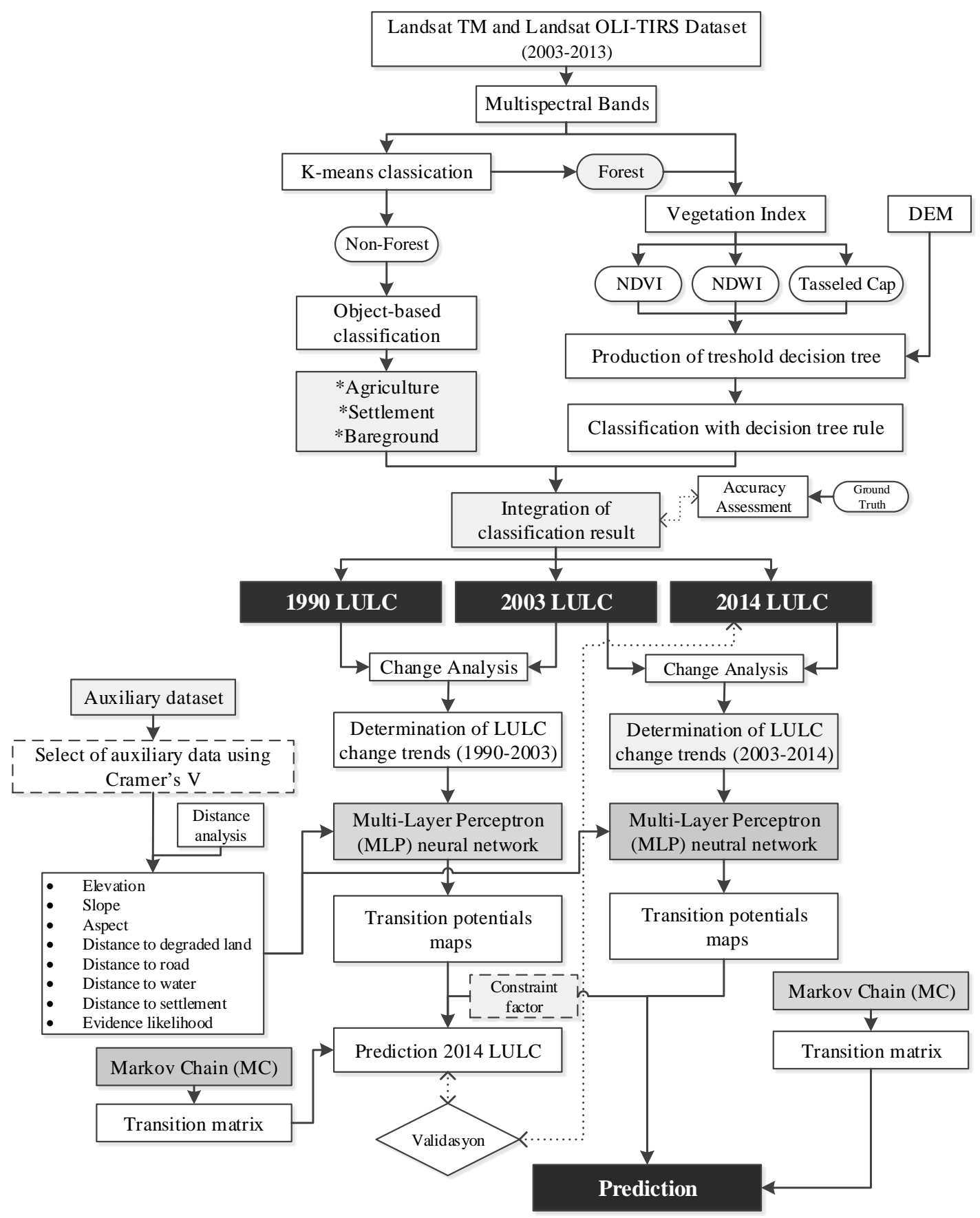

Figure 2. Flow diagram of the study

\section{Hybrid classification for land use land cover (LULC)}

A hybrid classification was employed in this study by considering the landscape characteristics of the research area. The ground data showed a heterogeneous structure in terms of landscape characteristics largely in dense forest areas. Composition of structural features such as height, percent tree cover, diversity and stand mixture rates, 
make the separation of target objects difficult during the classification of forest trees. Thus, pixel-based and object-based classification approaches were incorporated to extract accurate forest cover information. Combination of these two approaches improved the overall classification accuracy (Caproli, 2003; Satir et al., 2017; Tang and Pannell, 2013). Recent studies showed that combination of various classification methods called hybrid classification were efficiently used to tackle the problem of insufficient reference data. Hybrid classification takes the advantage of both supervised and unsupervised classification techniques (Al-doski et al., 2013; Kamusoko et al., 2011). The unsupervised classification (K-means) method was combined with decision tree and object-based classification methods. Hybrid classification takes advantage of both supervised and unsupervised classification techniques.

The hybrid classification for this study was implemented in five phases including: (i) K-means unsupervised classification approach for determining the forests and non-forest areas, (ii) generation of auxiliary variables from Landsat $5 \mathrm{TM}$ and Landsat 8 OLI-TIRS for decision tree algorithm, (iii) statistical comparison of auxiliary variables, (iv) objectbased classification of agriculture, bareground and settlements and (v) accuracy assessment. Post K-means clustering classification provided forest and non-forest covers. The forest cover was determined with using decision tree rule thought vegetation indices while non-forest cover was classified through object-based classification.

\section{Vegetation indices}

The auxiliary variables including Normalized Difference Vegetation Index (NDVI), Normalized Difference Water Index (NDWI) and Tasseled Cap were derived as ancillary data from Landsat images (Table 2). NDVI was used widely to assess the relationship between spectral variability and the changes in vegetation growth (Bilgili et al., 2014). NDWI is sensitive to changes in water content of vegetation canopies. RS of water in plants is an important application in forestry and agriculture (Satir et al., 2016). Tasseled Cap transformation reduces the Landsat reflectance bands into three orthogonal indices including brightness, greenness and wetness (Ozyavuz et al., 2011).

\section{Unsupervised classification ( $K$-means)}

The K-means unsupervised classification is a well-known algorithm uses a simple clustering algorithm based on pixel similarities. The algorithm works in three steps, (i) grouping objects $\mathrm{K}$ points into the space represented by the object that are being clustered and these point represent initial group centroids, (ii) assigning each object to the group that has the closest centroid, (iii) as all objects have been assigned, revised the positions of K centroids (Abbas et al., 2016; Giri, 2012; Usman, 2013). The purpose of the K-mean unsupervised classification was applied for determination of forest and nonforest cover type.

\section{Decision tree classification}

Decision tree (DT) classification combines both machine learning algorithm and knowledge based data mining technique. It is an efficient tool for LULC classification as a non-parametric approach, particularly in areas facing class mixing problem (Punia et al., 2010). DT is simple, flexible and efficient in classification process noisy and nonlinear relation between features both numeric and categorical inputs (Friedman, 1977; Pal and Mather 2003). 
Tree structure in decision tree approach is formed in three basic parts called nodes, branches and leaves. Each feature is represented by a node. The dataset is categorized according to the decision structure defined by the tree, by moving downwards and dividing subparts until reaching a leaf in sequence. The tree is composed of root a node, a set internal nodes an set a terminal nodes (Friedl and Brodley, 1997; Jiang et al., 2011). Each node has only one parent node and more descendant nodes (Figure 3). The decision tree creates decision rules by gathering the answers to the questions.

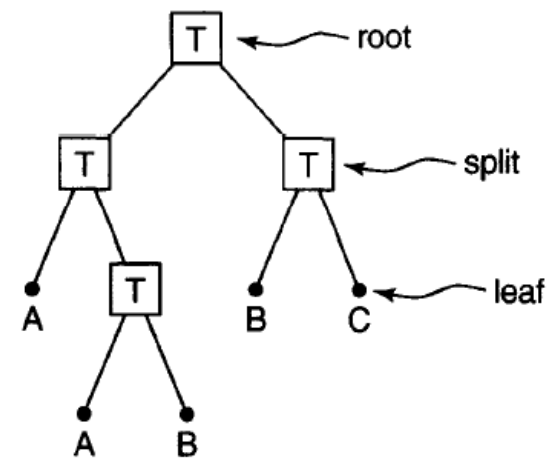

Figure 3. A decision tree classifier (Friedl and Brodley, 1997)

The main input of decision tree classification technique were auxiliary variables for this study. The forestlands were derived using K-means unsupervised classification method. The threshold values for DT structure rules collected from auxiliary dataset that generated from satellite sensor images.

\section{Object classification}

Object-based classification is useful to analyze groups of contiguous pixels as objects instead of using the conventional pixel-based classification unit. It is being a effective alternative to the traditional pixel based methods (Yu et al., 2006). In contrast to pixelbased classification methods that classify individual pixels directly, object-based classification first aggregates image pixels into spectrally homogenous image objects using an image segmentation algorithm and then classifies the individual objects (Liu and Xia, 2010). Kettig and Landgrebe (1976) proposed this idea and developed the spectral-spatial classifier called extraction and classification of homogeneous objects (ECHO). More recently, some research has adopted this method on land-use or landcover classification combined with image interpretation knowledge and classification results were significantly improved.

Cukurova plain located in lower part of the study area is a productive agricultural plain and agricultural activities continue throughout the year. Single satellite sensor image is insufficient to map agricultural crop pattern in Cukurova region due to high crop variation and seasonality (Satir and Berberoglu, 2012). Object based classification was used to classify agriculture, settlement and barerock areas accurately. Therefore, multi-temporal images of 1990, 2003 and 2014 were classified using nearest neighborhood algorithm together with multi-resolution segmentation. The heterogeneity of the segments was adjusted experimentally. Agricultural, settlement and barerock areas were classified with object based classification. 


\section{Markov chain for future LULC prediction}

Markov chain (MC) analysis has been widely used for LULC modelling which is a stochastic process that takes into account the past state to predict the future changing of variables over time (Brown et al., 2000; Muller and Middleton, 1994). The key factor for a MC is transition probability matrix which defines change trends from past to present and into the future for a certain class type for each grid. The probability matrix is a set of conditional probabilities for the cell to change to a particular new state and takes into consideration several variables that correspond to potential drivers and constrains of change (Berberoglu et al., 2016). MC uses Cellular Automata (CA) approach for the future simulations. $\mathrm{CA}$ is a theoretical framework that permits computational experiments in spatial arrangements over time (Clark, 2008). The basic components of the CA approach is identified with the cells, a neighborhood function, transition probabilities, time and space. Markov modelling requires LULC suitability maps for each LULC classes.

\section{Multi-layer perceptron (MLP)}

There are six generally used ANN models for pattern recognition; Hopefield network, Hamming network, Carpenter/Grossberg classifier, Kohonen's self-organising feature maps, single layer perceptron and multi-layer perceptron. The multi-layer perceptron described by Rumelhart et al. (1986) is the most commonly encountered ANN model in remote sensing because of its successful generalization capability and only this one is considered in this study. This type of ANN model consist of three or more layers which are generally interconnected to the previous and next layers, but there are no interconnections within a layer, each layer consists of processing elements called unit or nodes. The first layer is called the input layer and serves as a distribution structure for the data being presented to the network. Its holds input values and distributes these values to all units in the next layer and so no processing is done at this layer. The input values can be spectral bands or additional information. The final processing layer is called the output layer and in this case is land cover classes. Layer in between input and output layers are termed hidden layers. The number of hidden layers and units within the network are defined by user.

LULC suitability map of each class as an output of MLP was input to model future LULC map of 2025. This process consisted of three stages (i) classification through decision tree approach, (ii) modelling transformation potential of each class using MLP, and (iii) modelling the future LULC with MC. LULC change map was derived using classified time-series of Landsat TM/OLI images. LULC conversion indicated transition potentials amongst the classes. This change map was linked with explanatory variables including, elevation, slope, aspect, distance to degraded land, distance to road, distance to water, distance to settlements and evidence likelihood, to model transformation potential of each class using MLP. That classifier can be run more efficient with less training data than parametric approaches (Dadhich, 2010a). This process is also called land suitability mapping which is implemented traditionally with multi-criteria approach through user defined settings like weighting and prioritizing land conversion suitability. This subjective process within this study was implemented using MLP with minimum user interference. In the final stage the resulted transformation potential maps for each LULC type utilized within MC approach. 
MC transformation matrices are used to predict the possible conditions of future land cover. However, MC is insufficient to reveal the distributions of spatial changes alone, whereas MLP neural networks allow modelling the general tendency in the trend determined by the change analysis. According to Eastman (2016), MLP-MC combination achieves the most accurate and most obvious results in terms of target transformations. These outcomes are usually assessed under the sub-models major transformations in which urban expansion or human-induced degradation are taken into account. The relation between the grouped transformations in the sub model structure and the driving force is determined by Cramer's $\mathrm{V}$ analysis. In this context, it is very important to classify past classification maps with high accuracy so that a reliable model can be performed. In addition, the real and simulated images providing $75 \%$ or more of a level of overlap lead to produce the future simulation with an acceptable accuracy. If the overlap between the real and simulated image is less than $75 \%$, the calibration process is applied. It is necessary to check the reliability of the classification maps or reexamine the environmental variables in the MLP-MC process.

\section{Result}

The result of this study were presented in three phases (i) multi-temporal LULC mapping and accuracy assessment, (ii) modelling transformation potential of each class using MLP, ROC statistic and (iii) modelling the future LULC with MC.

\section{Multi-temporal LULC mapping and accuracy assessment}

The LULC maps for 1990, 2003 and 2014 were derived by hybrid classification of Landsat imagines and auxiliary data (Table 2). Nine major LULC were classified as coniferous forest, deciduous forest, agriculture, bareground, water, settlement, barerock, sand dunes and grassland (Figure 4). The accuracy of classified images of 1990, 2003 and 2014 were derived using overall accuracy and Kappa statistics (Table 3).

Table 3. Accuracy assessment for LULC classification

\begin{tabular}{|c|c|c|c|c|c|c|}
\hline \multirow{2}{*}{ LULC class } & \multicolumn{2}{|c|}{1990} & \multicolumn{2}{|c|}{2003} & \multicolumn{2}{|c|}{2014} \\
\hline & $\mathrm{PA}(\%)$ & $\mathrm{UA}(\%)$ & $\mathrm{PA}(\%)$ & $\mathrm{UA}(\%)$ & $\mathrm{PA}(\%)$ & $\mathrm{UA}(\%)$ \\
\hline Coniferous forest & 78.0 & 97.9 & 90.3 & 87.9 & 86.2 & 90.3 \\
\hline Deciduous forest & 88.9 & 72.7 & 86.4 & 98.3 & 86.1 & 86.1 \\
\hline Agriculture & 70.6 & 83.0 & 84.1 & 84.1 & 93.5 & 82.7 \\
\hline Bareground & 93.8 & 88.4 & 87.2 & 81.7 & 83.3 & 80.6 \\
\hline Water & 100 & 100 & 96.6 & 96.6 & 94.7 & 94.7 \\
\hline Settlement & 96.3 & 100 & 93.5 & 95.6 & 88.9 & 88.9 \\
\hline Barerock & 82.7 & 92.9 & 84.0 & 85.7 & 73.3 & 91.7 \\
\hline Sand dunes & - & - & 70.6 & 85.7 & 84.6 & 84.6 \\
\hline Grassland & 82.3 & 83.0 & 85.3 & 87.9 & 85.7 & 94.7 \\
\hline Overall accuracy & \multicolumn{2}{|c|}{$91 \%$} & \multicolumn{2}{|c|}{$87 \%$} & \multicolumn{2}{|c|}{$88 \%$} \\
\hline Kappa statistic(KIA) & \multicolumn{2}{|c|}{0.89} & \multicolumn{2}{|c|}{0.85} & \multicolumn{2}{|c|}{0.87} \\
\hline
\end{tabular}

PA: Producer's accuracy, UA: User's accuracy 


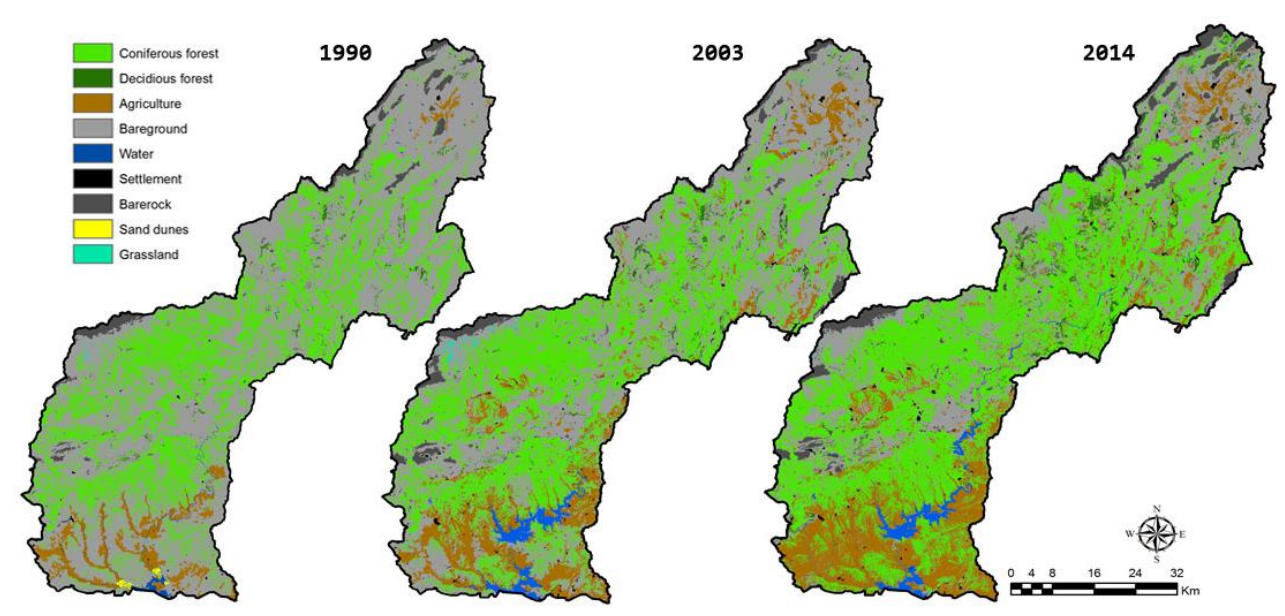

Figure 4. Hybrid classification results

Output of three classifications were cross-tabulated to determine from-to change (Table 4).

Table 4. Cross-tabulation of LULC changes (\%)

\begin{tabular}{|c|c|c|c|c|c|c|c|c|c|c|}
\hline \multirow{2}{*}{\multicolumn{2}{|c|}{ 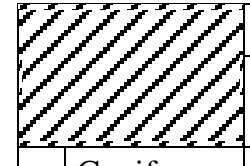 }} & \multicolumn{9}{|c|}{1990 LULC } \\
\hline & & $\begin{array}{c}\text { Coniferous } \\
\text { forest }\end{array}$ & \begin{tabular}{|c|}
$\begin{array}{c}\text { Deciduous } \\
\text { forest }\end{array}$ \\
\end{tabular} & \begin{tabular}{|c|} 
Agri- \\
culture
\end{tabular} & \begin{tabular}{|c|}
$\begin{array}{c}\text { Bare- } \\
\text { ground }\end{array}$ \\
\end{tabular} & Water & Settlement & \begin{tabular}{|c|} 
Bare- \\
rock
\end{tabular} & $\begin{array}{l}\text { Sand- } \\
\text { dunes }\end{array}$ & $\begin{array}{c}\text { Grass- } \\
\text { land }\end{array}$ \\
\hline \multirow{11}{*}{ 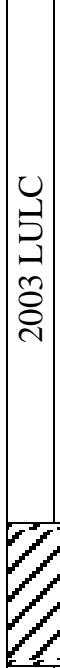 } & $\begin{array}{c}\text { Coniferous } \\
\text { forest }\end{array}$ & 82.91 & 0.87 & 0.53 & 15.02 & 0.31 & 1.69 & 0.07 & 0.32 & 4.51 \\
\hline & $\begin{array}{l}\text { Deciduous } \\
\text { forest }\end{array}$ & 0.45 & 76.0 & 0.34 & 0.83 & 0.11 & 0.02 & 0.00 & 0.01 & 0.03 \\
\hline & Agriculture & 0.73 & 1.07 & 78.93 & 10.15 & 11.96 & 4.91 & 0.04 & 11.63 & 0.00 \\
\hline & Bareground & 15.73 & 21.73 & 4.65 & 67.20 & 2.30 & 0.51 & 7.24 & 2.78 & 13.74 \\
\hline & Water & 0.09 & 0.21 & 14.67 & 0.91 & 85.09 & 1.06 & 0.00 & 84.75 & 0.00 \\
\hline & Settlement & 0.02 & 0.07 & 0.85 & 3.82 & 0.02 & 91.78 & 0.05 & 0.00 & 0.00 \\
\hline & Barerock & 0.06 & & 0.00 & 1.82 & .02 & & 92.58 & 0.00 & 1.34 \\
\hline & Sand d & 0.00 & 0.00 & 0.03 & 0.01 & 0.19 & 0.03 & 0.00 & 0.51 & 0.00 \\
\hline & Grassland & & 0.00 & 0.00 & 0.24 & 0.00 & 0.0 & 0.02 & 0.00 & 80.38 \\
\hline & & \multicolumn{9}{|c|}{2003 LULC } \\
\hline & & $\begin{array}{c}\text { Coniferous } \\
\text { forest }\end{array}$ & \begin{tabular}{|c|}
$\begin{array}{c}\text { Deciduous } \\
\text { forest }\end{array}$ \\
\end{tabular} & \begin{tabular}{|c|} 
Agri- \\
culture
\end{tabular} & \begin{tabular}{|c|}
$\begin{array}{c}\text { Bare- } \\
\text { ground }\end{array}$ \\
\end{tabular} & Water & Settlement & $\begin{array}{c}\text { Bare- } \\
\text { rock }\end{array}$ & $\begin{array}{l}\text { Sand- } \\
\text { dunes }\end{array}$ & $\begin{array}{c}\text { Grass- } \\
\text { land }\end{array}$ \\
\hline \multirow{9}{*}{ 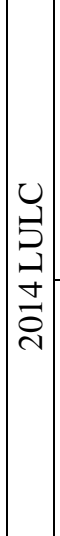 } & $\begin{array}{c}\text { Coniferous } \\
\text { forest }\end{array}$ & 85.69 & 21.11 & 4.74 & 12.41 & 0.56 & 1.74 & 2.21 & 1.68 & 6.46 \\
\hline & $\begin{array}{c}\text { Deciduous } \\
\text { forest }\end{array}$ & 1.22 & 54.15 & 0.36 & 0.55 & 0.28 & 0.08 & 0.09 & 0.00 & 0.19 \\
\hline & Agriculture & & & 79.43 & 9.36 & 4.91 & 3.73 & 0.92 & 26.51 & 1.60 \\
\hline & Bareground & 11.49 & 23.03 & 12.9 & 73.38 & 11.22 & 3.63 & 3.77 & 0.73 & 52.93 \\
\hline & Water & & & 1.38 & 0.19 & 81.64 & 0.47 & 0.01 & 52.18 & 0.00 \\
\hline & Settlement & 0.07 & 0.05 & 0.99 & 2.13 & 0.11 & 90.15 & 0.06 & 0.00 & 0.01 \\
\hline & & & & 0.18 & 1.41 & 0.12 & 0.2 & 92.91 & 0.24 & 1.10 \\
\hline & & 0.01 & 0.01 & 0.02 & 0.00 & 1.10 & 0.00 & 0.00 & 18.66 & 0.00 \\
\hline & Grassland & 0.02 & 0.00 & 0.00 & 0.57 & 0.06 & 0.00 & 0.03 & 0.00 & 37.71 \\
\hline
\end{tabular}


This analysis indicated that agriculture, rural settlement, water surface and deciduous forestlands increased whereas, bareground decreased between 1990 and 2014 period. Forestlands covered $62.52 \%$ of the area in 1990 however it decreased to $48.52 \%$ in 2003 and further decrease took place in 2014 to $30.91 \%$. Major conversion of forestlands was to agriculture and grasslands over time.

\section{Modelling transformation potential of each class using MLP}

LULC changes and their linkage to the explanatory variables were assessed and modelled through MLP. Firstly, the change was grouped and then weighting values of the explanatory variables were determined within the MLP. The major LULC transformations were classified under major groups in the literature (Areendranet al., 2013; Basse et al., 2014; Eastman, 2016; Dadhich et al., 2010a; Megahed et al., 2015; Mishra and Rai, 2016; Ozturk, 2015). These groups are represented by current trends or major changes. For the study, transformation of semi-natural land cover to settlement and agriculture are detected as major changes due to intensive anthropogenic activities during the 1990-2014 (1990, 2003 and 2014) time period. Transformation potential of each LULC type was derived using eight variables including; (i) elevation, slope, aspect, distance to degraded land, distance to road, distance to water, distance to settlements and evidence likelihood and the six major LULC transformations were considered including; (i) from coniferous forest to settlement, (ii) from delicious forest to settlement, (iii) from bareground to settlement, (iv) from barerock to settlement, (v) from bareground to agriculture and (vi) from agriculture to bareground (Figure 5; Table 5).

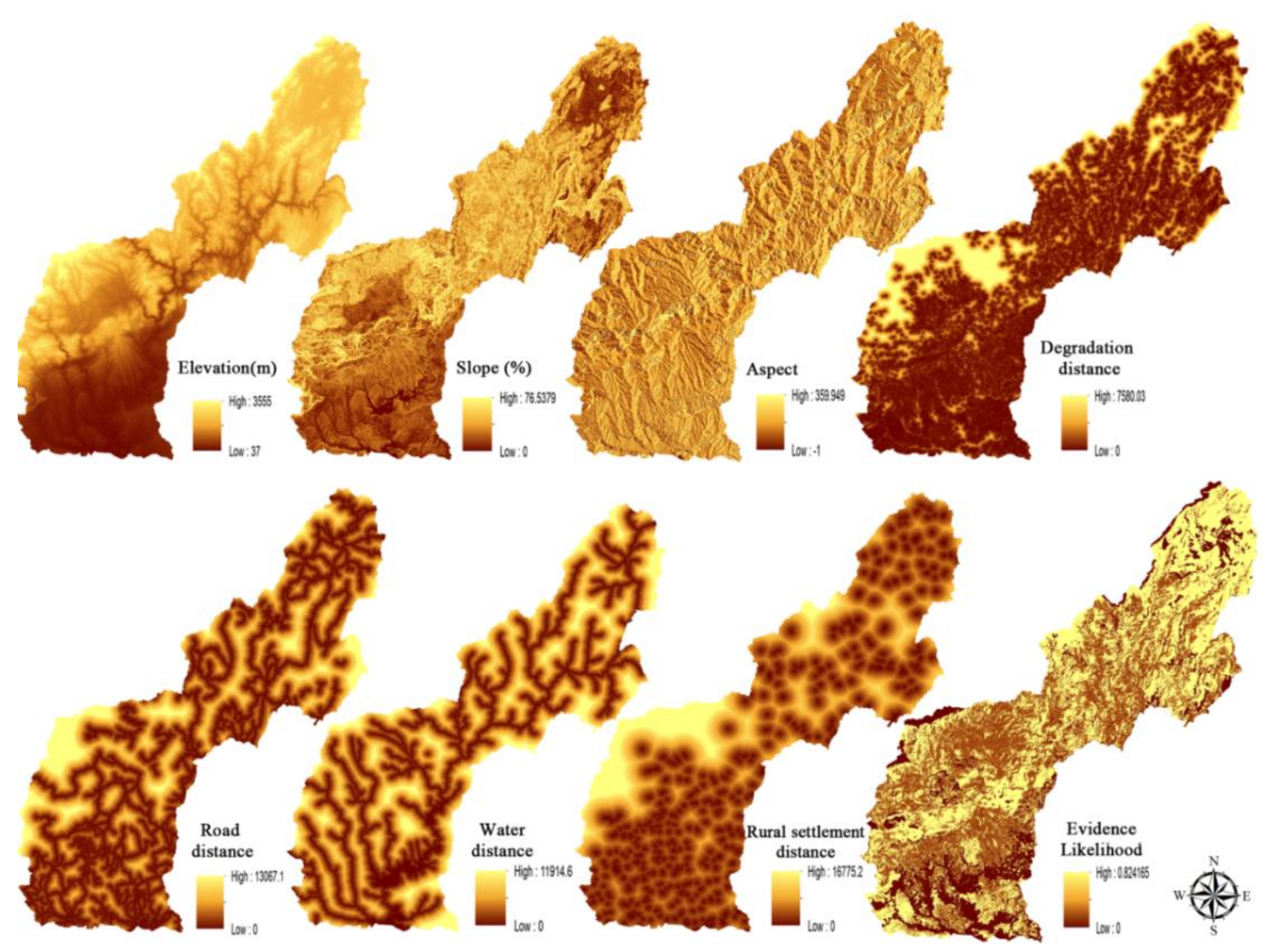

Figure 5. Input dataset for Multi-Layer Perceptron 
Table 5. Driving forces with Cramer's $V$

\begin{tabular}{c|c}
\hline Driving force & Cramer's V \\
\hline Elevation & 0.62 \\
Slope & 0.39 \\
Aspect & 0.33 \\
Distance to degraded land & 0.37 \\
Distance to road & 0.49 \\
Distance to water & 0.27 \\
Distance to settlement & 0.41 \\
Evidence Likelihood & 0.45 \\
\hline
\end{tabular}

The current trend of change was indicated that afforestation activities are intense in the region. As a result of afforestation, $1253.55 \mathrm{~km}^{2}$ area was converted to coniferous forest from bareground between the years of 1990 and 2014. On the other hand, adverse effects of anthropogenic impacts such as conversion from bareground to agriculture and settlement took place approximately $986.36 \mathrm{~km}^{2}$ (Figure 6).

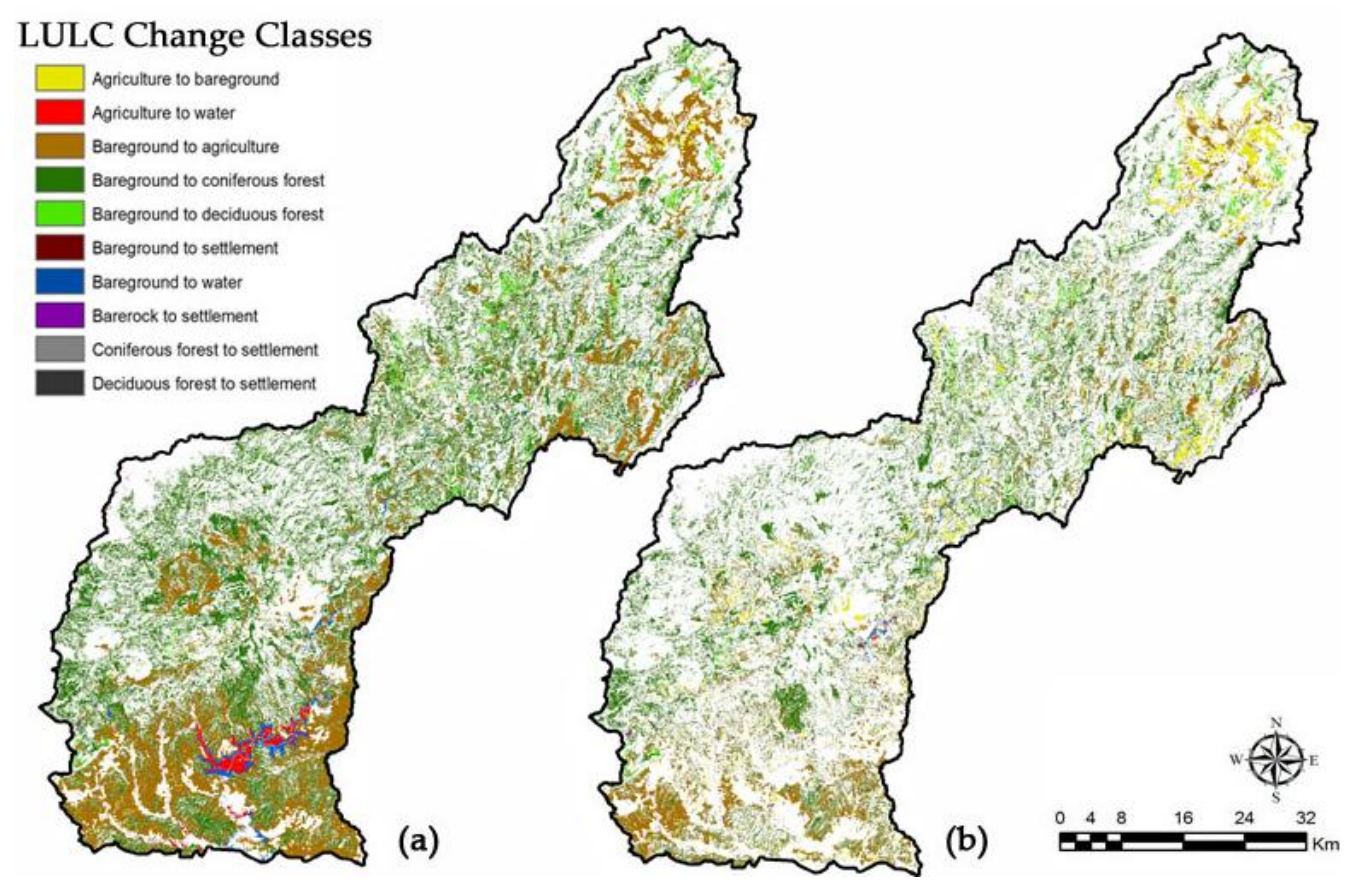

Figure 6. Change detection result maps (major transformation) (a) from 1990 to 2003 and (b) from 2003 to 2014

The LULC transitions were linked to explanatory variables in a GIS environment to model transformation potential using MLP. The spatial variables, which affected the land cover change were considered as driving forces. Explanatory variables were determined through literature survey and expert knowledge on land change dynamics of this region. Training set of MLP consisted of six target variables which represent the major LULC transitions and eight driving forces. Training of MLP neural network was evaluated by Cramer's V test. This is the most common method explaining the effects 
of spatial variables in land cover changes. Cramer's V value was calculated with Equation 1 (Cramer, 1999):

$$
V=\sqrt{\frac{x^{2}}{N(m-1)}}
$$

$\mathrm{x}^{2}$ : Chi-square,

$\mathrm{N}$ : Population

$\mathrm{m}$ : The numbers of the columns or lines on the table

Static or dynamic properties of spatial variables were identified through Cramer's V. While static variables have a stable characteristic that has not changed over time, dynamic variables can change due to anthropogenic effects over time. In this regard, distance from degradation, distance from road and distance from settlement were identified as dynamic factors and the others were considered as static. The Cramer's V results were considered as weighting values of spatial variables and integrated to MC for future modelling. Categorical maps can be converted into continuous maps using the Evidence Likelihood transformation based on the relative frequency of pixels belonging to the different categories within areas of change (Mas et al., 2014).

The MLP model was trained with $75 \%$ of the data and tested with $25 \%$. The ideal MLP training variables were defined experimentally given in Table 6. According to result of MLP model process between training and test dataset was observed $76.10 \%$ accuracy rate.

Table 6. MLP model variable value and accuracy rate

\begin{tabular}{c|c}
\hline Variables & Results \\
\hline Hidden layer nodes & 17 \\
Start learning rate & 0.01 \\
End learning rate & 0.001 \\
Momentum factor & 0.5 \\
RMS & 0.01 \\
Iteration & 6000 \\
Training RMS & 0.15 \\
Testing RMS & 0.17 \\
Accuracy rate (\%) & 76.10 \\
Skill measure & 0.7302 \\
\hline
\end{tabular}

The production of potential change maps by taking advantage of the transformations were input data set required for MC analysis (Mishra, 2016). The number of outputs of the transformation potential maps (Figure 7) are equal to the number of major change input groupings. The spatial variables maps were standardized between 0 and 1 . The standardization process in between of spatial variable was obtained through MLP transition model results.

Additional testing process was performed for the simulation of 2014. Weights of transition potential images were derived through MLP. This process is also called the model calibration. MC approach was used these transition potential images of 1990 and 2003 to simulate 2014 LULC map. Comparison of the 2014 observed and predicted maps were given in the Figure 8 . 


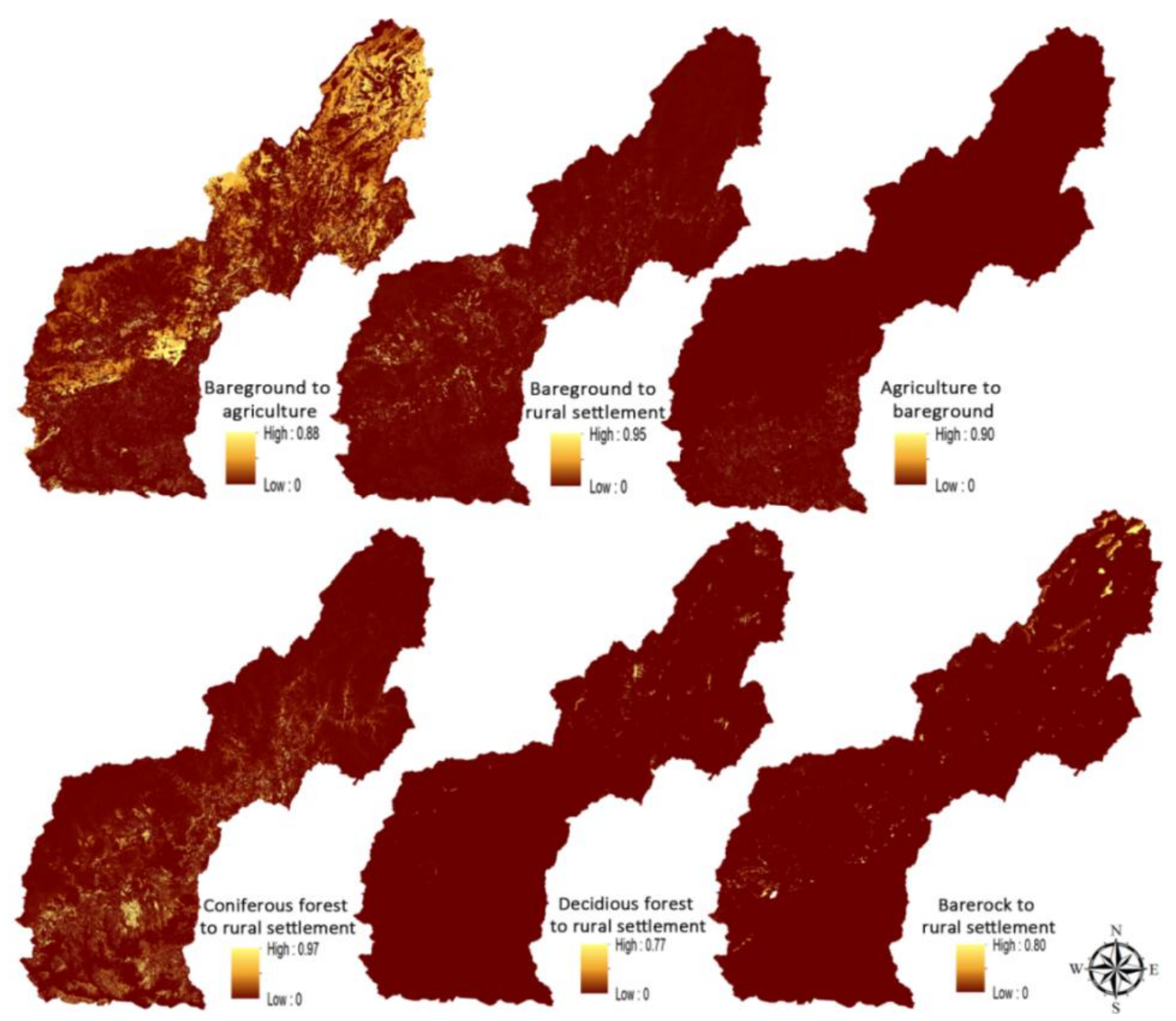

Figure 7. Transition probability maps of major transition categories

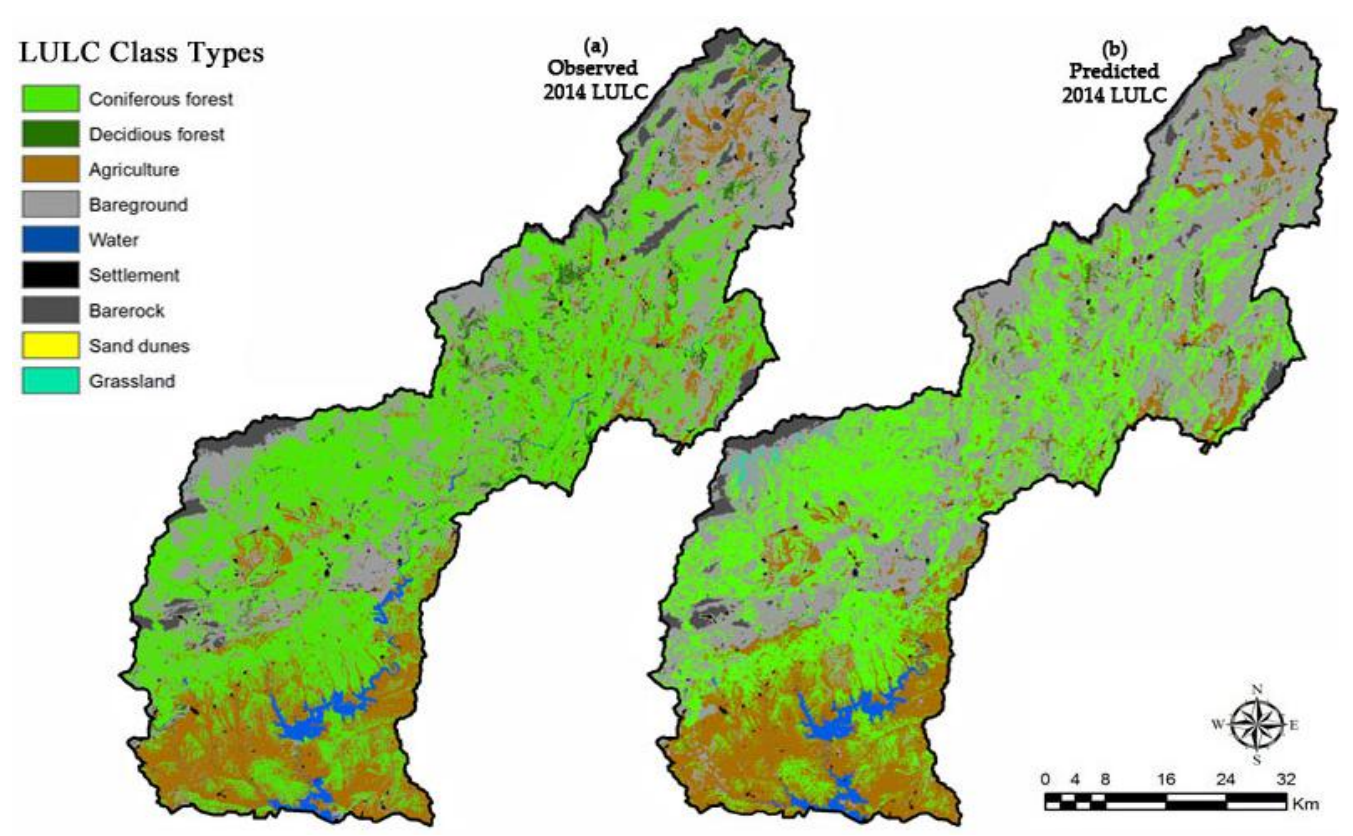

Figure 8. 2014 LULC observed and predicted maps

APPLIED ECOLOGY AND ENVIRONMENTAL RESEARCH 16(1):467-486.

http://www.aloki.hu • ISSN 15891623 (Print) • ISSN 17850037 (Online)

DOI: http://dx.doi.org/10.15666/aeer/1601_467486

(c) 2018, ALÖKI Kft., Budapest, Hungary 
A cross classification analysis was performed for the validation process between the observed and predicted 2014 maps and the Kappa Index of Agreement (KIA) was calculated. KIA indicated the level of overlap between the observed and predicted 2014 LULC types and found as 0.79. Crammer (1999) stated that acceptable accuracy of the model should be $\geq 0.70$ in LULC modelling studies. In addition to the KIA, validity of the outputs were evaluated using Receiver Operating Characteristic (ROC) analysis. The main goal of the ROC analysis was to evaluate the performance of the spatial models in selected grid cells that generate possibility in the process of modelling a given phenomenon or situation (Berberoglu et al., 2016; Hamdy et al., 2017). According to testing by correlation method that ROC was obtain 0.89 , as for there is high correlation between selected spatial variables and LULC types.

\section{Future prediction of the $L U L C$}

LULC of 2025 was estimated after the validation of the model. Major transformations were grouped according to the LULC trends from past to present and future LULC map was produced as an outcome of transition potentials (Figure 9).

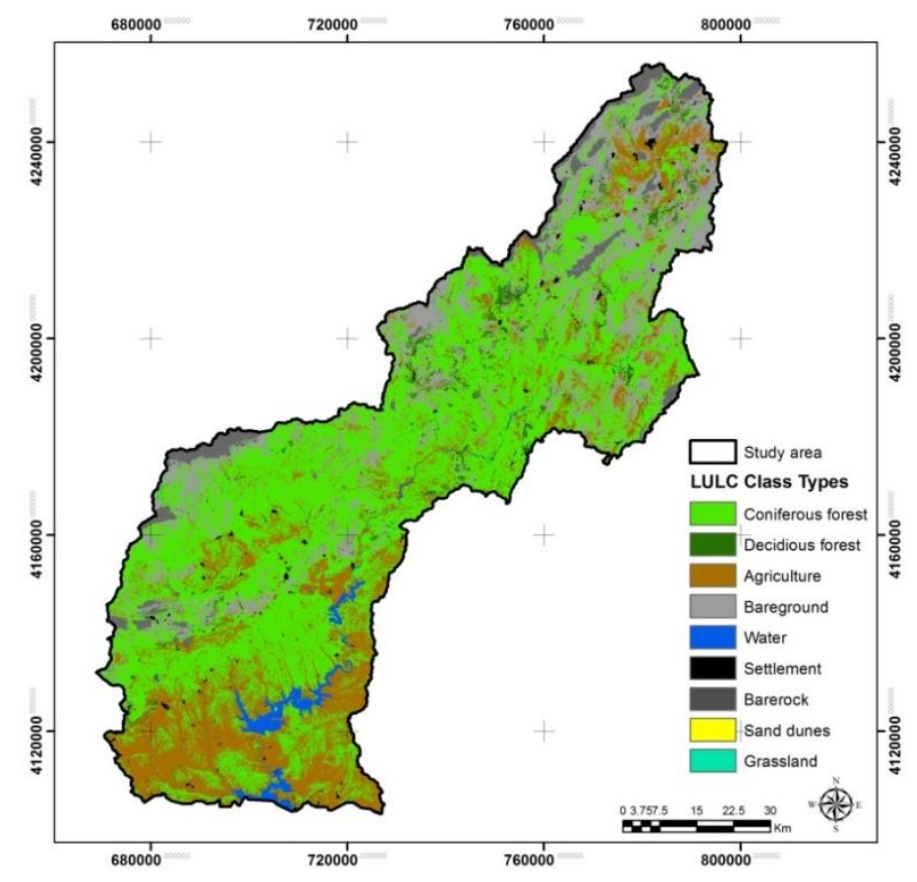

Figure 9. Predicted LULC map for 2025

According to modelling results, an increase of $13.43 \%$ was observed in forest areas between 1990 and 2014 time periods. As a result of this trend, MLP-MC simulated forestland coverage as $50.83 \%$ of the total area (Table 7).

It can be stated that the main reason for forest growth was afforestation activities. During the period of past 10-15 years, afforestation were carried out by the Adana Forest General Directorate. However, it was not only the afforestation, but also the microclimatic factors resulted from newly established dams in the study area. Establishments of new dams caused an increase in humidity and triggered the regeneration of the forestlands in the region. This change was also resulted an increase 
in agricultural fields due to irrigation opportunities. Thus, it is clearly seen that agricultural areas are expanding while the dam and water surface are increased. According to the LULC classification and change analysis results the forestlands have been transformed to the larger forest and farmlands whereas, minor changes were observed in dune and pasture areas.

Table 7. LULC coverage of classified and simulated images

\begin{tabular}{c|c|c|c|c}
\hline LULC class types & $\begin{array}{c}\mathbf{1 9 9 0} \text { area } \\
(\boldsymbol{\%})\end{array}$ & $\begin{array}{c}\mathbf{2 0 0 3} \text { area } \\
(\mathbf{\%})\end{array}$ & $\begin{array}{c}\mathbf{2 0 1 4} \text { area } \\
(\mathbf{\%})\end{array}$ & $\begin{array}{c}\mathbf{2 0 2 5} \text { area } \\
(\mathbf{\%})\end{array}$ \\
\hline Coniferous forest & 28.85 & 33.42 & 43.19 & 50.83 \\
Deciduous forest & 0.91 & 1.31 & 2.25 & 2.31 \\
Agriculture & 4.09 & 11.45 & 16.73 & 22.24 \\
Bareground & 62.52 & 48.52 & 30.91 & 17.60 \\
Rural settlement & 0.36 & 0.59 & 0.61 & 0.74 \\
Barerock & 2.61 & 2.88 & 4.39 & 4.33 \\
Water & 0.49 & 1.75 & 1.85 & 1.88 \\
Grassland & 0.05 & 0.07 & 0.05 & 0.06 \\
Sand dunes & 0.11 & 0.01 & 0.01 & 0.01 \\
\hline
\end{tabular}

\section{Discussion and conclusion}

This study produced past and present LULC by using the hybrid classification approach and 2025 simulation map was also generated based on the change dynamics derived from the different dated LULC maps. The dominant regional landscape characteristics were rural widely shaped by the forestlands.

Major steps of the research can be summarized as; i) LULC mapping with hybrid classification approach and object based classification for more accurate and sensitive results, ii) analyzing the quality and quantity of LULC change with the postclassification technique in order to determine major LULC transformations, iii) preparation of explanatory variables that effect the major LULC transformations and generating of transition probability maps through the MLP and iv) validation of the model calibration and 2025 LULC simulation map with the MC model. The subjected analyses were largely performed with the free of charge Landsat images acquired from the Landsat data archive.

Having altitude difference, fertile soil structure and suitable climatic conditions the study are allocated in the southern east Mediterranean region of Turkey has features that enable the expansion of forest and agricultural areas. According to World Reference Base (WRB) international soil classification system updates in 2014 by Aydin et al. (2016), 67.43\% of the study area is in Leptosol-Cambisols soil class. The LeptosolCambisols of the area is intersect with limeness brown forest soils and brown forest soils. These soils have a characteristic which are formed on the parent material containing high lime and have high capacity of water-holding and nutrients, natural drainage system and on which shrub and mixed forest can grow. Therefore, the bareground has been transformed into agricultural and especially coniferous forest class due to anthropogenic effects. According to findings of the study, the bareground decreased by $31.61 \%$ from 1990 to 2014 , while the forest areas increased by $15.68 \%$ and agricultural areas increased by $12.64 \%$. In research of Tanriover (2012), the main 
reason for increase in agricultural areas are the population growth of Adana city that in the southern part of the study area, after 1980 and additionally the facilitated irrigation opportunities provided through the dams built on Seyhan River. Furthermore the expansion of forest areas has been determined. It can be stated showing a positive structure for LULC in major changes, afforestation regulations at Adana Forest General Directorate have been successful in the increase of the forest areas. In addition to afforestation, it has been emphasized in a study investigated climate change effect across Turkey by Berberoglu et al. (2014) that forest increase in the northern parts of the eastern Mediterranean region may be an impact of global change. In this direction, the forest increases in the northern part of the research area are parallel to the study of Berberoglu et al. (2014).

Future land cover predictions with the MLP-MC method was experienced in the rural landscape for the study however, it can be also conveniently applied in urban landscapes. The success of the model is mostly depended on the accurate LULC classification and here of presentative LULC transformations. In this frame, MLP analysis was tested for the study area and detected as a useful tool in determining the suitability maps which is one of the most critical steps in the future modelling of MC. The relevance of the auxiliary data was tested using Cramer's V coefficient during the production of suitability maps. This relationship facilitates the production of more objective transition probability maps. Actually, Multi Criteria Analysis (MCA) is the most common method used in determining the weighting values for preparation of suitability maps in MC modelling (Ahmed and Ahmed, 2012; Akin, 2014; Berberoglu et al., 2016; Jafari, 2017; Kamusoko, 2011; Sayemuzzaman and Iha, 2014). However, this method comes in for criticism due to user intervention during the weighting process. So, this study integrated MC modelling and Multi-Layer Perceptron (MLP) within a neural network interface in order to determine more objective weighting values for the future modelling. One limitation of the MLP-MC analysis was found that the model is unable to generate transition possibilities for all LULC classes. It is necessary to determine major LULC conversion trends and then the model produces transition potential accordingly. This makes the model difficult to use in a wide variety of LULC transitions exist especially in semi-natural areas.

In conclusion, over the past decade remote sensing data enabled the application of hybrid classification approach which is a combination of parametric and non-parametric techniques. This research was demonstrated that MLP-MC integration was beneficial to estimate future LULC of Mediterranean region where LULC change dynamics are complex due to environmental gradients and thousands of years of intensive human activities. Prediction performance of MLP-MC for future LULC was evaluated by ROC coefficient (0.89). Coniferous forest and agricultural areas were statistically distinct as they are expected a large increase in 2025. It should be noted that increase of temperature as a result of climate change will be resulted change in the borders of forest species from south towards to north in the Mediterranean Basin.

\section{REFERENCES}

[1] Abbas, A. W., Minallh, N., Ahmad, N., Abid, S. A. R., Khan, M. A. A. (2016): K-Means and ISODATA Clustering Algorithms for Landcover Classification Using Remote Sensing. - Sindh University Research Journal (Science Series) 48(2): 315-318. 
[2] Ahmed, B., Ahmed, R. (2012): Modelling urban land cover growth dynamic using multitemporal satellite images: a case study of Dhaka, Bangladesh. - ISPRS International Journal of Geo-Information 1(1): 3-31. DOI: 10.3390/ijgi1010003.

[3] Al-doski, J., Mansor, B. S., Shafri, H. Z. M. (2013): Image classification in remote sensing. - Journal of Environment and Earth Science (JEES) 3: 141-148.

[4] Akin, A., Aliffi, S., Sunar, F. (2014) Spatio-temporal urban change analysis and the ecological threats concerning the third bridge in Istanbul city. - The International Archives of Photogrammetry Remote Sensing and Spatial Information Science, Istanbul, Turkey.

[5] Areendran, G., Raj, K., Mazumdar, S., Puri, K., Shah, B., Mukerjee, R., Medhi, K. (2013): Modeling REDD+ baselines using mapping technologies: A pilot study from Balpakram-Baghmara Landscape (BBL) in Meghalaya, India. - International Journal of Geoinformatics 9(1): 61-71.

[6] Aydin, G, Cullu, M. A, Ersahin, S., Akca, E., Erdogan, E., Atanır, L., Yorulmaz, A., Cilek, A., Ersoy, M., Miavaghi, S., Kapur, S., Lal, R. (2016): Turkey: Mapping Soil Carbon Stock. - In: Lal, R. (ed.) Encyclopedia of Soil Science, 3rd edition. Taylor\&Francis, USA. DOI: 10.1081/E-ESS3-120052900.

[7] Basse, R. M., Omrani, H., Charif, O., Gerber, P., Bodis, K. (2014): Land use changes modelling using advanced methods: Cellular automata and artificial neural networks. The spatial and explicit representation of land cover dynamics at the cross-border region scale. - Applied Geography 53: 160-171. DOI: 10.1016/j.apgeog.2014.06.016.

[8] Berberoglu, S., Hickler, T., Kapur, S. Ozkan, C., Kucuk, O., Donmez, C., Akin, A., Erdogan, M. A., Cilek, A., Forrest, M., Kirkby, M., Irvine, B., Ersoy, M. Sahingoz, M. (2014): Climate Change and Environment Risk Analysis in Turkey. - Cukurova University-Johann Goethe University TUBITAK \& IntenC Project (110Y338).

[9] Berberoglu, S., Akin, A., Clarke, K. C. (2016): Cellular automate modelling approaches to forecast urban growth for Adana, Turkey: A comparative approach. - Landscape and Urban Planning 153: 11-27. DOI: 10.1016/j.landurbplan.2016.04.017.

[10] Bilgili, B. C., Satir, O., Muftuoglu, V., Ozyavuz, M. A. (2014): Simplified method for the determination and monitoring of green areas in urban parks using multispectral vegetation indices. - Journal of Environmental Protection and Ecology (JEPE) 15(3): 1059-1065.

[11] Brown, D. G., Pijanowski, B. C., Duh, J. D. (2000): Modeling the relationships between land use and land cover on private lands in the Upper Midwest, USA. - Journal of Environmental Management 59: 247-263. DOI: 10.1006/jema.2000.0369.

[12] Caproli, M., Leone, A., Ripa, M. N., Tarantino, E. (2003): A Hybrid Land Cover Classification of Landsat-7 ETM+ Data for an Efficient Vegetation Mapping. - In: Camarda, D., Grassini, L. (eds.) Local Resources and Global Trades: Environments and Agriculture in the Mediterranean Region. CIHEAM, Bari.

[13] Chapin, F., Matson, P., Vitousek, P. M. (2011): Principles of Terrestrial Ecosystem Ecology, 2nd ed. - Springer, New York.

[14] Civco, D. L. (2007): Artificial neural networks for land-cover classification and mapping. - International Journal of Geographical Information Systems 7(2): 173-186. DOI: $10.1080 / 02693799308901949$.

[15] Clark, K. (2008): A Decade of Cellular Urban Modelling with SLEUTH: Unresolved Issues and Problems. - In: Brail, R. K. (ed.) Planning Support Systems for Cities and Regions. Lincoln Institute of Land Policy, Cambridge, MA.

[16] Conte, M., Nelson, E., Carney, K., Fissore, C., Olwero, N., Plantinga, A. J., Stanley, B., Ricketss, T. (2011): Terrestrial carbon sequestration and storage. - In: Kareiva, P., Tallis, H., Ricketts, T. H., Daily, G. C., Polasky, S. (eds.) Natural Capital Theory and Practice of Mapping Ecosystem Services, 1st ed. Oxford University Press Inc., New York.

[17] Cramer, H. (1999): Mathematical Methods of Statistics. Princeton Landmarks in Mathematics and Physics, 9th ed. - Princeton University Press, Princeton. 
[18] Dadhich, P. N., Hanaoka, S. (2010): Markov Method Integration with Multi-layer Perceptron Classifier for Simulation of Urban Growth of Jaipur City. - 6th WSEAS International Conference on Remote Sensing (REMOTE '10). Iwate Prefectural University, Japan.

[19] Dadhich, P. N., Hanaoka, S. (2010): Remote Sensing, GIS and Markov's Method for Land Use Change Detection and Prediction of Jaipur District. - Journal of Geomatics ISG 4: 9-15.

[20] Donmez, C., Berberoglu, S., Cilek, A., Evrendilek, F. (2016): Spatiotemporal modeling of net primary productivity of eastern Mediterranean biomes under different regional climate change scenarios. - International Journal of Environmental Research 10(2): 341356.

[21] Eastman, J. R. (2016): TerrSet Geospatial Monitoring and Modelling System. - Clark Labs, Clark University, Worcester, USA.

[22] Elaalem, M. M., Ezlit, Y. D., Elfghi, A. (2013): Abushnaf. Performance of Supervised Classification for Mapping Land Cover and Land Use in Jeffara Plain of Libya. International Conference on Food and Agricultural Sciences, Singapore. - IACSIT Press, Singapore.

[23] Friedman, J. H. (1977): A recursive partitioning decision rule for nonparametric classification. - IEEE Trans. Compt. C-26: 404-408.

[24] Friedl, M. A., Brodley, C. E., (1997): Decision tree classification of land cover from remotely sensed data. - Remote Sensing Environmental 61: 399-409.

[25] Giri, C. P. (2012): Brief Overview of Remote Sensing of Land Cover. - In: Giri, C. P., Weng, Q. (eds.) Remote Sensing of Land Use and Land Cover: Principles and Applications. Taylor \& Francis, CRC Press, USA.

[26] Hamdy, O., Zhao, S., Salheen, M. A., Eid, Y. Y. (2017): Analyses the Driving Forces for Urban Growth by Using IDRISI ${ }^{\circledR}$ Selva Models Abouelreesh - Aswan as a Case Study. International Journal of Engineering and Technology (IJET) 9(3): 226-232. DOI: 10.7763/IJET.2017.V9.975.

[27] Jafari, M., Majedi,H., Monavari, S. M., Alesheikh, A. A., Zarkesh, M. K. (2017): Dynamic simulation of urban expansion through a CA-Markov model Case study: Hyrcanian region, Gila, Iran. - European Journal of Remote Sensing 49(19): 513-529. DOI: 10.5721/EuJRS20164927.

[28] Jiang, L., Wang, W., Yang, X., Xie, N., Cheng, Y. (2011): Classification Methods of Remote Sensing Image Based on Decision Tree Technologies. - In: Li, D., Liu, Y., Chen, Y. (eds.) CCTA, Part 1, IFIP AICT. International Federation for Information Processing, Laxenburg.

[29] Jakubauskas, M. E., Lulla, K. P., Mausel, P. W. (1990): Assessment of vegetation change in fire altered forest landscape. - Photogrammetric Engineering and Remote Sensing 56(3): 301-310.

[30] Kamusoko, C., Oono, K., Nakazawa, A., Wada, Y., Nakada, R., Hosokawa, T., Tomimura, S., Furuya, T., Iwata, A., Moriike, H., Someya, T., Yamase, T., Nasu, M., Gomi, Y., Sano, T., Isobe, T., Homsysavath, K. (2011): Spatial simulation modelling of future forest cover change scenarios in Luangprabang Province, Lao PDR. - Forests 2(3): 707-729. DOI: 10.3390/f2030707.

[31] Kettig, R. L., Landgrebe, D. A. (1976): Classification of multispectral image data by extraction and classification of homogeneous objects. - IEEE Transactions on Geoscience and Remote Sensing 14(1): 19-26.

[32] Lal, R. (2004): Soil Carbon Sequestration Impacts on Global Climate Change and Food Security. - Science 304: 1623-1627. DOI: 10.1126/science.1097396.

[33] Liu, D., Xia, F. (2010): Assessing object-based classification: advantages and limitations. - Remote Sensing Letters 1(4): 187-194. 
[34] Mas, J. F., Kolb, M., Paegelow, M., Omedo, M. C., Houet, T. (2014): Modelling land use/cover changes: a comparison of conceptual approaches and softwares. Environmental Modelling and Software 51: 94-111.

[35] Masud, S., Ali, Z., Haq, M., Ghuri, B. M. (2016): Monitoring and Predicting Landuse/Landcover Change Using an Integrated Markov Chain \& Multilayer Perceptron Models: A Case Study of Sahiwal Tahsil. - Journal of GeoSpace Science 2: 43-59.

[36] Megahed, Y., Cabral, P., Silva, J., Caetano, M. (2015): Land Cover Mapping Analysis and Urban Growth Modelling Using Remote Sensing Techniques in Greater Cairo Region-Egypt. - ISPRS International Journal of Geo-Information 4: 1750-1769. DOI: 10.3390/ijgi4031750.

[37] Merchant, J. W., Narumalani, S. (2009): Integrating Remote Sensing and Geographic Information Systems. - In: Warner, A. T., Nellis, M. D., Foody, G. M. (eds.) The SAGE Handbook of Remote Sensing, 1st ed. SAGE Publications Inc., New Delhi.

[38] Mishra, V. N., Rai, P. K. (2016): A remote sensing aided multi-layer perceptron Markov chain analysis for land use and land cover change prediction in Patna district (Bihar), India. - Arabian Journal of Geosciences 9: 249-266. DOI: 10.1007/s12517-0152138-3.

[39] Muller, M. R., Middleton, J. A. (1994): Markov model of land-use change dynamic in the Niagara region Ontario, Canada. - Landscape Ecology 9(2): 151-157. DOI: 10.1007/BF00124382.

[40] Ozdogan, M. (2016): Image Classification Methods in Land Cover and Land Use. - In: Thenkabail, P. S. (ed.) Remotely Sensed Data Characterization, Classification, and Accuracies - Remote Sensing Handbook. CRC Press Taylor \& Francis, USA.

[41] Ozturk, D. (2015): Urban growth simulation of Atakum (Samsun, Turkey) using cellular automata-Markov chain and multi-layer perceptron-Markov chain models. - Remote Sensing 7(5): 5918-5950. DOI: 10.3390/rs70505918.

[42] Ozyavuz, M., Satir, O., Bilgili, B. C. (2011): A change vector analysis technique to monitor land-use/land-cover in the Y1ldı Mountains, Turkey. - Fresenius Environmental Bulletin (FEB) 20(5): 1190-1199.

[43] Pal, M., Mather, P. M. (2003): An assessment of the effectiveness of decision tree methods for land cover classification. - Remote Sensing Environmental 86: 554-565.

[44] Punia, M., Joshi, P. K., Porwal, M. C. (2010): Decision tree classification of land use land cover for Delhi, India using IRS-P6 AWiFS data. - Expert Systems with Applications 38(5): 5577-5583. DOI: 10.1016/j.eswa.2010.10.078.

[45] Rumelhart, D. E., Hinton, G. E., William, R. J. (1986): Learning internal representation by back-propagation errors. - In: Rumelhart, D. E., McClelland, J. L., PDP Research Group (eds.) Parallel Distributed Processing: Explorations in Microstructure of eCognition. MIT Press, Cambridge, MA.

[46] Satir, O., Berberoglu, S. (2012): Land Use/Land Cover Classification Techniques Using Optical Remotely Sensed Data in Landscape Planning. - In: Ozyavuz, M. (eds.) Landscape Planning, 1st ed. INTECH, Rijeka. DOI: 10.5772/31351.

[47] Satir, O., Berberoglu, S. (2016): Crop yield prediction under soil salinity using satellite derived vegetation indices. - Field Crops Research 192: 134-143. DOI: 10.1016/j.fcr.2016.04.028.

[48] Satir, O., Berberoglu, S., Akca, E., Yeler, O. (2017): Mapping the dominant forest tree distribution using a combined image classification approach in a complex Eastern Mediterranean basin. - Journal of Spatial Science 62(1): 157-171. DOI: 10.1080/14498596.2016.1212414.

[49] Sayemuzzaman, M., Jha, M. K. (2014): Modelling of future land cover land us change in North Carolina using Markov chain and cellular automate model. - American Journal of Engineering and Applied Sciences 7(3): 295-306. DOI: 10.3844/ajeassp.2014.295.306.

[50] Singh, P., Singh, S. (2011): Landuse pattern analysis using remote sensing: a case study of Mau District, India. - Scholars Research Archives of Applied Sciences 3: 10-16. 
[51] Tang, Y., Pannell, C. W. (2013): A hybrid approach for land use/land cover classification. - GIScience \& Remote Sensing 46(4): 365-387. DOI: 10.2747/1548-1603.46.4.365.

[52] Tanriover, A. A. (2012): Modelling the urban growth of adana using remote sensing and geographical information system. - PhD Thesis. Department of Landscape Architecture, Cukurova University, Adana, Turkey.

[53] Usman, B. (2013): Satellite Imagery Land Cover Classification using K-Means Clustering Algorithm Computer Vision for Environmental Information Extraction. Elixir International Journal Computer Science and Engineering 63: 18671-18675.

[54] Young, R. H., Potchin, M. (2016): Typology/Classification of Ecosystem Services. OpenNESS, University of Nottingham. United Kingdom.

[55] Yu, Q., Gong, P., Clinton, N., Biging, G., Kelly, M., Schirokauer, D. (2006): Objectbased detailed vegetation classification with airborne high spatial resolution remote sensing imagery. - Photogrammetric Engineering \& Remote Sensing 72(7): 799-811. 